Revista Iberoamericana, Vol. LXXI, Núm. 213, Octubre-Diciembre 2005, 1015-1028

\title{
SOMBRA TERRIBLE DE UN ANTIHÉROE: ESTRATEGIAS PARA UN CANON FACCIOSO
}

\author{
POR \\ Lelia Area \\ Universidad Nacional de Rosario
}

Nations themselves are narrations.

Edward Said (1993)

La siguiente propuesta tiene por objeto releer dos momentos, dos capítulos -podríamos decir- de uno de los más grandes relatos (en sentido figurado, pero también considerándolo desde toda su carnalidad material) de la escritura argentina del siglo XIX. Un relato pensado como novela, la novela argentina de Juan Manuel de Rosas y la lectura de dos de sus inscripciones paradigmáticas, “el” Facundo (1845) de Domingo Faustino Sarmiento y "el” Rozas (1898) de Lucio V. Mansilla.

En un sentido amplio, esta novela podría ser pensada como un gesto narrativo que ocupa -y preocupa- a gran parte de los escritores de ese siglo quienes aparecen como los diseñadores de un libro, escrito a lo largo de más de cinco décadas, libro al que se le fueran incorporando sucesivos capítulos, todos ellos de una consistencia tal como para convertise en gestos fundacionales. Libro que encarna, imaginariamente, los tonos y temas de una biblioteca facciosa ${ }^{1}$ "armada” desde el proceso de ficcionalización de la figura de Juan Manuel de Rosas como cuerpo histórico / corpus literario; grilla de lectura a través de la cual los sujetos y objetos tramados por el cuerpo bibliotecológico del rosismo articularan escenas significantes y facciosas que me permitieron analizar los modos de leer una época.

Recordemos: el movimiento de la Revolución de Mayo, que surgiera como un intento de liberalización de las relaciones económicas con la corona, tuvo entre sus consecuencias más notorias, la instalación de la violencia como forma de vida, ya que derivó en una sucesión de guerras civiles donde ciudad y campaña se enfrentaron a lo largo de setenta

${ }^{1}$ Por biblioteca pretendo instalar una figura de lectura que opere como referencia de esa maravillosa imagen narrativa que alguna vez nos "regalara” Jorge Luis Borges cuando (casi) felizmente concluye en "La biblioteca de Babel” que "la Biblioteca perdurará [a la especie humana]: iluminada, solitaria, infinita, perfectamente inmóvil, armada de volúmenes preciosos, inútil, incorruptible, secreta. / Acabo de escribir infinita. /... / Yo me atrevo a insinuar esta solución del antiguo problema: La biblioteca es ilimitada y periódica. Si un eterno viajero la atravesara en cualquier dirección, comprobaría al cabo de los siglos que los mismos volúmenes se repiten en el mismo desorden (que, repetido, sería un orden del Orden)" (470-71, énfasis mío). En este contexto, digamos que la "modalidad" facciosa, además de referir a una acción beligerante, también remite "a la otra cara" de algo. 
años. Fueron guerras de las ciudades que se imaginaban europeas contra el español, con el objeto de instalar lo europeo como cultura, pero simultáneamente fueron guerras de caudillos provinciales contra esas mismas ciudades dado que, ellos también, buscaban otro tipo de independencia. Una independencia que -como dirá Sarmiento-tendrá que ver con "librarse de toda sujeción civil y desenvolver su carácter y su odio contra la civilización. Las ciudades triunfan de los españoles y las campañas de las ciudades” (Facundo 49). La anarquía generada por el choque violento de estos dos imaginarios de país -puestos por primera vez en contacto al reclutarse los ejércitos de la independenciaabre una trama narrativa político-literaria en el territorio argentino, que gira en torno a una figura central: la figura de Juan Manuel de Rosas. Es precisamente en este período cuando se produce un cambio significativo en la relación que mantenía hasta entonces el intelectual con la política, pudiéndose observar cómo desde el punto de vista del discurso literario, del discurso histórico, del discurso político, la figura de Rosas -ya sea a través de sus seguidores como de sus detractores- se instala en el marco de una historia de legitimación de proyectos concretos.

Rosas, poderoso estanciero de Buenos Aires y hábil político, en poco más de una década logra dar realidad a la unificación del país, concretando en su persona la "suma del poder público” e imponiendo su autoridad sobre el resto del convulsionado territorio argentino. Desde el principio su figura provoca sentimientos de adhesión o rechazo y se convierte en materia de discusión; ${ }^{2}$ una discusión provocada por la misma práctica política que pone en juego con indiscutible sagacidad: aparentar el apoyo a una clase mientras propicia la consolidación de otra. En este marco, Rosas aparece como referente tanto político cuanto literario para un grupo de jóvenes que, desde las "elites letradas" de Buenos Aires y el interior, pretenden ser considerados la instancia alternativa de un proyecto de país que mira estrábicamente a Europa. Adscribiendo a una retórica romántica de la sensibilidad, la generación de 1837 intenta diseñar -lo que en este caso significa “escribir”- el momento fundacional de la nación.

Sabemos: 1837 opera como el hito de origen de esa generación que comienza a escribir la Argentina-nación con los tonos de una novela política. La búsqueda del origen involucra un elemento regenerador; es la preocupación por hallar lo primigenio, lo que no tiene antecedentes, el tiempo fuerte en que se fijan los rasgos del espíritu popular, el que los artistas deben escrutar para plasmarlo en sus obras, caos que deviene orden por la mediación del logos y que vuelve al pueblo, debidamente compuesto, por una segunda mediación, la que el intelectual cumple precisamente entre el logos y el pueblo (Matamoro).

\footnotetext{
${ }^{2}$ Adolfo Prieto considera que el “complejo proceso político-social vivido entre 1820 y 1852 [...] se desarrolló sobre la enconada y suicida lucha de dos facciones: unitarios y federales. Ambas facciones representaban una distinta concepción política y diversos intereses económicos. enfrentadas desde los comienzos mismos de la Revolución de Mayo, una y otra corriente se habían esterilizado en un confuso forcejeo, hasta que arrojaron al flamante país en las puertas de la anarquía” (70). Así, "el rosismo constituyó un verdadero trauma de la conciencia colectiva, un golpe que escindió a la sociedad de su tiempo en réprobos y elegidos, condenando a los dos sectores a la mutua recriminación. La literatura de esos años agigantó y volvió más espesa la sustancia de un conflicto típicamente maniqueo, y la literatura posterior, desgajada de las bases históricas y sociales que le dieron origen, continuó, sin embargo, reviviendo en la conciencia colectiva las viejas tensiones del conflicto” (87).
} 
La vuelta al origen obliga a una reflexión crítica sobre la historia patria y, en sentido contrario, es una imposición de la misma historia vivida. Los jóvenes del 37 aceptan el programa de la revolución pero no sus consecuencias históricas; ha sido un plan correcto que ha degenerado, por lo que se impone el tiempo de su regeneración.

Es precisamente en ese tiempo que Rosas ha llegado por segunda vez al poder, en este caso, como el indiscutido jefe de su provincia de Buenos Aires y cuando se les aparece a todos como un hecho irreversible y destinado a gravitar durante décadas sobre la vida del territorio nacional. El grupo de jóvenes proveniente de las elites letradas de Buenos Aires y del interior se declara destinado a tomar el relevo de la clase política que ha guiado al país desde la revolución de independencia hasta el fracaso del intento de organización unitaria de 1824-1827: fracaso evidente, si se evalúa el triunfo en todo el territorio nacional, en general, y en Buenos Aires, en particular, de los amenzantes jefes federales.

Frente a ese grupo unitario relegado por el paso del tiempo y aniquilado por el fracaso, se erige el nuevo grupo que se autodefine como la Nueva Generación. Si ese fracaso unitario puede ser ubicado en el fatigado espacio de supervivencia del iluminismo, la Nueva Generación se coloca bajo el signo del romanticismo y por lo tanto se considera mejor preparada para asumir la función directiva. Esta noción fundante -la de soberanía de la clase letrada, justificada por la posesión exclusiva del sistema de ideas de cuya aplicación dependía el cuerpo político (y no solo político) de la nación- explica el entusiasmo con que la Nueva Generación asume de Cousin el principio de la soberanía de la razón, convicción que Esteban Echeverría hace doctrinaria cuando en 1838 escribe el Credo de la Joven Generación.

La avasalladora pretensión de constituirse en guías del nuevo país (y su justificación por la posesión de un salvador sistema de ideas que no llegan a definirse con precisión) está destinada a alcanzar una influencia, tal vez, menos evidente en lo inmediato pero incuestionablemente más atribuible al nuevo grupo generacional de 1837. Heredera de ella es la idea de acción y enfrentamiento políticos, la que para encontrar su justificación debe plantearse como imposición a una Argentina que en cuarenta años de revolución no ha encontrado, todavía, su forma.

En 1837, entonces, la Nueva Generación se ve como la única guía política posible para la nación. Pero...está Rosas. Rosas que representa el único -y el último- obstáculo para el advenimiento de una etapa utópica de paz y progreso. Nacido de la revolución, su existencia puede darse en el marco de tensiones que su figura protagoniza, alguna veces, y propicia, otras. Una figura que adquiere carácter mitológico a través de la mitográfica desarrollada tanto por sus enemigos como por sus aliados. Una mitográfica que hace de la figura-Rosas un emblema fundacional a través del cual se parte y reparte el cuerpo real, imaginario y simbólico de eso que se intenta pensar como la nación argentina moderna.

Pero, también sabemos que cuando la figura-Rosas adquiere -para estos jóvenes-la tonicidad de personaje narrativo la operación es de tal magnitud que su transcendencia y proyección tienen la particularidad de balancearse indefinidamente en el fiel de una balanza cuyas polaridades son la historia, por un lado, y la ficción, por el otro. O tal vez -y tensionando esta afirmación un poco más- podríamos decir que esa figura-Rosas se instala en la historia por lo que de construcción ficcional implica al mismo tiempo que se ficcionaliza al no poder dejar de ser (y hacer) la historia. Desde este marco, me propuse 
exponer la figura de Juan Manuel de Rosas como una figura encarnada en el nombre que contaminaría tanto el cuerpo político como el corpus literario de un canon faccioso, conservatorio y traductor de los tonos con que la violencia política se inscribió en el espacio literario.

En nuestro caso, resulta más que interesante constatar cómo esta afirmación se ve resignificada, curiosamente, desde las brillantes evaluaciones de un historiador como Emilio Ravignani, quien afirmara que

\begin{abstract}
De Rosas puede decirse lo que el historiador Albert Vandal dijera de Bonaparte: "la leyenda precedió a su historia”. Fue de entre todos los personajes del período anterior a la organización nacional y dentro de la categoría de los llamados caudillos -a nuestro juicio, también ha sido un hombre de gobierno- el más adulado a la par que el más odiado y el más combatido; característica que ha trascendido hasta nuestra época no sólo al género histórico, sino también a la novela, al melodrama y a la conciencia popular. Casi se diría que el conocimiento de Rosas es algo así como una roja noticia de corte policial. (13)
\end{abstract}

Existe, entonces, un modo de narrar al que podríamos denominar Rosas -con mayúscula- que desata una verborragia discursiva mientras noveliza la escritura políticoliteraria del siglo xIx en Argentina. En este sentido, la historia de la Argentina como nación ha sido -y sigue siendo- leída con más fuerza desde sus textos literarios que desde los mismos textos de historia, dado que aquellos han señalado no solo el modo de leer sino también el modo de imaginar una nación. Esta afirmación parte, obviamente, de considerar a la forma-novela en sentido extendido, es decir como esa forma cultural que funda actitudes, referencias y experiencias en el imaginario de una época al mismo tiempo que realiza el gesto de decirlo. Desde sus tramas narrativas organiza el espacio de la ficción modalizándolo como historia, bloqueando otras narraciones emergentes o en formación.

Es a partir de esta matriz imaginaria que me interesaría hacer jugar la novela argentina de Juan Manuel de Rosas, diseño ficcional político/literario que funda (y se funda en) su condición de posibilidad a partir de la relación que establece con la figura emblemática enunciada más arriba. Recordemos que David Viñas (Literatura argentina... 4), alguna vez, expuso el dilema cuando planteó que "la literatura argentina empieza con Rosas", sentencia con la que apuntaba (y sigue apuntando), sin ninguna duda, a señalar el espacio canónico que la figura cultural Rosas fundó en el imaginario narrativo de su época. Sentencia, asimismo, que nos propone la necesidad de pensar la historia de la escritura en la Argentina como una historia de inscripciones, las que se han visto materializadas en textos que exponen la particularidad de ser marcas de lectura proyectivas y progresivas a lo largo de los últimos dos siglos. En la necesidad de configurar un espacio que ha sido problemático, violento, desordenado, esta escritura ha emergido a través de los modos de leer una escena nacional cuyo acento característico está en la actualidad de sus marcas; proyectada desde un horizonte de negatividad, afirma lo que no es, aquello sobre lo que no va a tratar, aquel a quien no va a nombrar. Es por ello que frente a tal paradoja narrativa el lector se ve impelido de leer los actos de la historia escritos como literatura. Paradoja narrativa que abre una perspectiva casi ritual donde se rechaza lo puramente referencial al mismo tiempo que se instala un espacio donde juegan -y se juegan- las versiones. 
Versiones que no se presentan como literales sino que aparecen como literarias ya que conservan el tono persistente de una estrofa sin fin cuyo eje articula una pobre certeza: la de ser verdades insistentemente alteradas.

Estas puras apariencias tienen la ironía de leerse como un exceso de realidad cuyo único relieve es el de la anacronía pensada como esa figura involutiva del tiempo y del espacio. Es precisamente a partir de este marco que los gestos de fundación se muestran como posibles y la generación del 37 se propone escribir una nación. Ellos ven el territorio a través de una figura doble: desierto/Rosas, espacio imposible, escenario de un proyecto de versiones literarias con las que harán política. Desde esa escena discursiva, el territorio nacional señalado como desierto se figura tanto como tema literario cuanto como problema político: se tematiza como patrimonio y, al mismo tiempo, se lo dramatiza como vasta soledad. Genera los relatos de un espacio imposible, mientras juega a ser el escenario de un proyecto de innovación literaria, que intenta silenciar una voz del presente evaluado como catástrofe: la voz del Héroe (¿Pater?) del Desierto, ${ }^{3}$ es decir, la voz de Rosas. Para esa voz, otras voces no menos potentes aunque sí más literarias se alzan configurando el canon para una biblioteca facciosa fundante de una literatura de nación.

En consecuencia: para leer la escritura literaria argentina del siglo xix hay que asumir los tonos que la conformación de la nación intenta desplegar por el solo hecho de querer aparecer desde un registro institucional. Sin embargo, el gesto de fundación no es solo institucional dado que la historia se ha escrito -también- con literatura. Dado, entonces, que la literatura expone sus modos de decir la historia genéricamente, aceptando los matices que le otorgan las versiones, mezclando sus significaciones, adoptando marcos desarticulados en sí mismos, mi propuesta tiene por objeto detenerse en dos momentos de esos modos de decir:

a) Facundo-Sarmiento (1845), es decir, el proyecto político-literario que se enfrenta a Rosas mientras asume la ejemplaridad de ser una biografía moral que enmascara el afán de escribir la otra, aquella que por ser inmoral se proyecta al futuro como novela de la historia, $\mathrm{y}$

b) Rozas-Mansilla (1898), un ensayo de evaluación del proyecto de constitución de la nación a partir de las escenas de familia que Lucio V. Mansilla encarna y asume. Desde el incómodo lugar de un sobrino que intenta novelar a ese tío, el causser escribe sobredeterminado por el peso de una conciencia histórica mortificada.

Así, desde gestos novelizadores de la figura Rosas totalmente equidistantes, Sarmiento / Mansilla construyen lectores -también-anacrónicos a quienes siempre tienen en cuenta. Con tonos diversos exponen sus modos de leer la historia y fundan lecturas que hacen con lo político, literatura. Facundo-Sarmiento/Rozas-Mansilla, dos páginas de un mismo libro, dos partes de un solo libro, escrito con la distancia de tiempo necesaria (aunque no suficiente) como para que el desarrollo histórico intente dar una evaluación de los proyectos de nación llevados a cabo a lo largo del siglo.

\footnotetext{
${ }^{3}$ Recordemos que en ocasión de una campaña contra los indios, en 1833, Rosas logró desplazar la frontera de Buenos Aires hasta el Río Salado. Su triunfo lo hizo merecedor del título de "Héroe del Desierto".
} 
1. (1845) FACUndo, el Rosas de Faustino

\begin{abstract}
En lugar de escribir el Facundo, como pretende, ha escrito el Faustino, como el libro lo demuestra, pues las ideas, las cosas y los intereses económicos que Facundo sostuvo como agente de Rosas, son los que hoy sirve y sostiene el biógrafo de Facundo, como instrumento del orden de intereses que se encarnó en Rosas.
\end{abstract}

Juan Bautista Alberdi (13)

Hayden White planteaba que la narrativa histórica no llega a desarticular las falsas creencias sobre el pasado, la vida humana, la naturaleza de una comunidad, sino que expone la forma en que la ficción -que siempre ha sido señalada como la modalidad específica de lo literario- presenta a partir de sus construcciones las pautas constitutivas de los acontecimientos imaginarios. Es por ello que la narrativa histórica podría ser considerada como un discurso que dice una cosa y significa otra. En el caso del Facundo de Sarmiento, esta operación puede ser estudiada a partir de su explicitación, dado que el escritor la expone como el objetivo mayor de su texto. No deja de ser interesante enfrentarse a dicho objetivo desde la “Introducción a la edición de 1845” dado que en ella, el escritor argentino se ve en la obligación de darnos ciertas pistas que funcionen con el carácter de pautas de lectura a seguir. Microrrelato programático en sí mismo la introduccióngrilla asume los tonos del texto a partir de su acápite, desde el cual se exige del historiador que abandone todo rasgo de impasibilidad. ${ }^{4}$ Faustino "asume" la ímproba misión de descifrar el enigma que la esfinge argentina propone al exponer la necesidad de "estudiar prolijamente las vueltas y revueltas de los hilos que lo forman y buscar en los antecedentes nacionales, en la fisonomía del suelo, en las costumbres y tradiciones populares, los puntos en que están pegados” (Facundo 241).

A través de dicho estatuto, ese Sarmiento acuña la novela-Rosas enmascarada en la alegoría-Facundo, dado que a partir de esta última no ve (y, en consecuencia, no escribe acerca de):

un caudillo simplemente, sino [de] una manifestación de la vida argentina tal como la han
hecho la colonización y las peculiaridades del terreno a lo cual creo -Sarmiento, agrega-
necesario consagrar una seria atención, porque sin esto la vida y hechos de Facundo
Quiroga son vulgaridades que no merecerían entrar sino episódicamente en el dominio
de la historia. Pero, Facundo, en relación con la fisonomía dela naturaleza grandiosamente
salvaje que prevalece en la inmensa extensión de la República Argentina; Facundo,
expresión fiel de una manera de ser de un pueblo, de sus preocupaciones e instintos;
Facundo, en fin, siendo lo que fue, no por accidente de su carácter, sino por antecedentes
inevitables y ajenos de su voluntad, es el personaje histórico más singular, más notable,
que puede presentarse a la contemplación de los hombres que comprenden que un
caudillo que encabeza un gran movimiento social no es más que un espejo en que se

${ }^{4}$ Privilegiada por Sarmiento del Cours de Litèrature [sic] de Villemain, la cita subraya que: "Je demande à l' historien l' amour justice impartiale ne doit être impassible. Il faut, au contraire, qu' il souhaite, qu' il espère, que’ il souffre, ou soit heureux de ce qu' il raconte” (240). 
reflejan, en dimensiones colosales, las creencias, las necesidades, preocupaciones y hábitos de una nación, en una época de su historia. (247)

El movimiento en la construcción significante que Sarmiento lleva a cabo es claro: la alegoría diseñada será ejemplar por lo que de singular tiene como personaje simbólico dado que si atravesamos el texto para llegar a otros de sus lugares -es decir, si avanzamos transversalmente desde la “Introducción” a la “Tercera parte: Gobierno Unitario. Presente y Porvenir”- observaremos que el personaje toma vida propia y da encarnadura al "monstruo que nos propone el enigma de la organización política de la República” (9). El monstruo deja de ser cifra para tener historia y -todos lo sabemos- la historia, para poder ser contada, debe actualizar matices. Matices que dicen tanto de aquel que la escribe como del que la hace, ya que si bien a este se lo expone, a aquel se lo señala a partir de su relación de compromiso con el objeto hecho historia. Un compromiso que, al decir de Sarmiento, es con aquel historiador del cual se exigía el amor a la humanidad o a la libertad y una justicia imparcial para que no fuera un impasible y del que se pretendía que deseara, supiera esperar, sufriera o disfrutara de lo relatado.

Escritura y política es la fórmula, parece decirnos Sarmiento mientras acalla que, sin Rosas, no solo no hubiera existido el Facundo, sino que tampoco el Faustino; algo que también ejecuta la generación de 1837 en la medida en que sus "narraciones" intentan silenciar los valores de la inscripción que Rosas realiza en el cuerpo político del territorio nacional. Narración literaria/inscripción política, términos opositores que devienen en las múltiples dicotomías fundacionales que la época tanto propone como expone: unitarios/ federales; destierro/tierra; ciudad/desierto; civilización/barbarie (Area y Parodi). Es precisamente en este sentido que la novelización sarmientina asume como impronta el rasgo que la desata cuando explícitamente confiesa que:

Para mí no hay más que una época histórica que me conmueva, afecte o interese, y es la de Rosas. Éste será mi estudio único, en adelante, como fue combatirlo mi solo estimulante al trabajo, mi solo sostén en los días malos. / "Si alguna vez hubiera querido suicidarme, esta sola consideración me habría detenido, como a las madres que se conservan para sus hijos”. (Citado por Palcos 83)

Novelización que hace de la biografía la trama privilegiada para exponer las estrategias discursivas de quien se instala como biógrafo y al hacerlo, emprende la tarea de ejercer una evaluación a través de la cual se castigue o se premie al biografiado con un “juicio” que mire a la posteridad. En este sentido, Sarmiento avanza en su propósito y afirma sin ambages ni rubores que:

Gusto a más de esto de la biografía. Es la tela más adecuada para estampar las buenas ideas; el que la escribe ejerce una especie de judicatura, castigando el vicio triunfante, alentando la virtud oscurecida. Hay en ella algo de las bellas letras, que de un trozo de mármol bruto puede legar a la posteridad una estatua. La historia no marcharía sin tomar de ella sus personajes, y la nuestra hubiera de ser riquísima en caracteres, si los que pueden, recogieran con tiempo las noticias que la tradición conserva de los contemporáneos. El aspecto del suelo me ha mostrado a veces la fisonomía de los hombres, y estos indican casi siempre, el camino que han debido llevar los acontecimientos. (Recuerdos 10) 
Esta confesión es paradigmática dado que Sarmiento, a lo largo de su vida, ha insistido en la escritura de la novela política argentina desde su pasión. Novela armada a partir de una lógica de predicados iracunda cuyo tono le hace confundirse en la paradoja que implicaba escribir el ser / no ser de Rosas. En este sentido resulta más que apropiado convocar la afirmación de Noé Jitrik cuando señalara que Sarmiento, al poner en escena un

[e]spíritu fundamentalmente acumulativo y efectista trata menos de demostrar que de convencer. Es fácil -agrega- determinar este objetivo: es como una suerte de presión que ejerce sobre el lector, cubriéndolo de datos como para que se entere de algo cuya enormidad o monstruosidad tiene fatalmente que condenar. Si el lector intuía por su propia cuenta que Facundo o Rosas eran bárbaros, Sarmiento refuerza su intuición mediante explicaciones encadenadas que representa como corroboraciones robustecidas por valores verbales de emoción y lirismo, pero cuya exactitud histórica no es solo variable sino que a veces es totalmente adulterada por el tono empleado en el relato, tono reconociblemente coercitivo. Lo histórico o lo sociológico es instrumentado por Sarmiento en función del convencimiento que aspira a lograra en su público. En este sentido, convencimiento parece opuesto a conocimiento, pero menos rigurosamente que se empleen tales conceptos. A la luz de esta oposición puede señalarse acaso que Sarmiento no explana su información confiando en la capacidad y el interés del aprendizaje del lector, sino que la utiliza con la finalidad de seducir o de encantar, fases, en suma, de un deseo profundo de convencer. De ahí que podamos afirmar que la exposición es regulada y tamizada en su espíritu en busca de una expresión suficiente, necesaria para hacer vibrar más cuerdas que la simple demostración histórica o racional, aunque se puede decir que también intenta esto último o cree hacerlo; básicamente, fundamentalmetne, se trata de conmover, de comprometer, de denunciar, de arrastrar, al mismo tiempo que se persigue el develamiento de ciertas incógnitas o la corrección de errores de comprensión. (11-2)

Uno de los aspectos más importantes que hay que, entonces, tener presente cuando se trabaja con Faustino es reconocer la novela que expone en el momento de figurar la complejidad del espacio político. Con esto pretendo decir que Sarmiento ficcionaliza sus saberes, y de esta forma su escritura adquiere el carácter de acto estético en el que convergen diferentes tramas genéricas: "una especie de poema, panfleto e historia” como él mismo la caracterizara en algún momento narrativo de su vida. Un campo de ficción que exige del lector que articule una constante operación de ajuste genérico con el objeto de poder atravesarlo. La contaminación de sus tramas discursivas es de tal magnitud que este lector siente, finalmente, que no tiene respiro para dirimir entre historia y ficción, acabando por abandonar la tarea, en manos de Faustino, por imposible. 
2. (1898) CuAndo SE ES SOBRino de Rosas...

La locura de Sarmiento lo validaba en su crispación romántica; la locura de Mansilla lo descalifica para la mirada positivista.

David Viñas (1975)

Lo primero que nos asalta cuando se intenta biografiar a Lucio Victorio Mansilla es el peso de una trilogía histórico-ficcional de la que le fuera imposible desprenderse: sobrino de Juan Manuel de Rosas, hijo del general Mansilla (cuñado de Rosas) y de Doña Agustina Ortiz de Rozas (hermana menor del “tirano”); una serie que agobia, aplasta y paraliza aun hoy a quien tan solo intente pensar acerca de lo que significa estar determinado -desde el nacimiento-por figuras emblemáticas de ese calibre. Lucio V. nos lo dice-o intenta decírnoslo-a través de esa verborrágica dispersión-que es lo mismo que decir esa interminable digresión- que es su escritura; una escritura que intenta "disparar" (en sentido bélico pero también en sentido coloquial) sobre y de esa trilogía que lo ha instalado en el imaginario histórico-político argentino del siglo xIx: la trilogía Rosas/ Mansilla/Rozas. A partir de la misma (o tal vez, podríamos decir, a causa de ella) solo se pueden contar anécdotas, fragmentos de recuerdos, memorias parciales, en los que el accionar siempre se hace en nombre de los otros.

En 1898, Mansilla escribe su Rozas, un libro que "no es, no puede ser, no debe ser ni una justificación ni un proceso [dado que sería] un libro de partido que no sustituyendo las realidades históricas a los disfraces de la leyenda, no haría sino aumentar la incertidumbre y las confusiones; [es por ello que será] un libro de buena fe, de completa y absoluta buena $f e$ " (13, énfasis mío). Teniendo en cuenta, entonces, este "propósito", me interesa destacar el carácter de emblema que posee la anécdota con la que Lucio intenta pensar/explicar la historia del nombre de su tío (la centralidad de la historia del tío que ubicará al sobrino siempre en el margen). Castigado Rosas por su madre a causa de una desobediencia, castigo que significaba encierro y penitencia a pan y agua, aguarda la noche. Cuando todos duermen, nos relata deslumbrado Mansilla:

falseó la cerradura, escribió con lápiz en un papel que puso en sitio visible unas palabras, se desnudó y casi como Adán salió a la calle yendo a casa de sus primos, los Anchorenas, a vestirse y conchabarse./ Al día siguiente, cuando fueron a llevarle el pan y el agua, hallaron el susodicho papel, el cual rezaba esto: "Dejo todo lo que no es mío, Juan Manuel de Rosas”, con s./ Y éste fue su primer acto de rebelión contra toda otra autoridad que no fuera su voluntad. Y de ahí que en lo sucesivo se firmara como no debía, puesto que su verdadero nombre patronímico era Juan Manuel Ortiz de Rozas, Rozas con z y no con s. (34)

Rosas (con s) operará siempre como contracara de Mansilla y este, a su vez, como una sinécdoque mortificada de aquel. La figura en tonos sarmientinos del tirano -una sombra terrible constantemente evocada- insiste desde puntos diversos en toda la escritura de Mansilla; y su insistencia tiene un registro de tal centralidad que los rasgos del sobrino adoptan la modalidad de lo que podríamos llamar anotaciones al margen. Mansilla anota 
al margen de esa figura desnuda, la que -a pesar de su desnudez- todavía puede desprenderse de aquello que considera que no le pertenece y fundarse con la escritura de otro nombre, el que sin embargo sonará igual y con mayor potencia que el anterior. Contracara perfecta de Mansilla, quién siendo al mismo tiempo un Mansilla más un Rozas, jamás habrá de sonar histórica o políticamente ni como el uno ni como el otro. Y es precisamente porque no suena que anota, ya no en el cuerpo del texto sino en sus márgenes.

En este sentido, no dejan de ser particularmente atractivas las relaciones de escritura que la figura Rosas ha desatado en la imaginación histórica del siglo XIX argentino, instalando una trama intelectual en el espacio de la oposición que funda el imaginario de nación a través de las escrituras de Echeverría, Sarmiento, Alberdi, Mármol, entre otros, es decir, una generación que desde la oposición al proyecto rosista se propone como alternativa única para dar a la Argentina su estatuto de modernidad. Sin embargo, no menos atractiva es la producción significante que esta figura generara a partir del espacio familiar, donde el enfrentamiento político o la enemistad partidaria eran vividas / sentidas como versiones, es decir, como relatos privados y, por lo tanto, hechas circular como temas de conversación (“¿Acaso en la misma familia -agrega- no se aseguraban antes, para desahogarse, de si alguien podía escuchar?”, 9). En este sentido, Mansilla confiesa tener

impresiones vivaces de aquellos tiempos en los que no padecimos, que nos obsesionan penosísimamente; y cuando pensamos que los que mataban eran hombres como nosotros, en cuyas rodillas cariñosas nos hemos sentado, ocúrresenos que pueden haber sido perdonados como inconscientes de crueldad -no así los que lo azuzaron. Quién sabe si no creían que matar era un remedio para tantos males como los que afligían al país. (citado por Prieto 138)

Mientras en el espacio del opositor el cuerpo político era partido (y repartido) en dicotomías tales como las de unitarios/federales; civilización/barbarie; europeísmo/ americanismo, en el familiar estas se veían atravesadas por un registro menos trágico al adquirir las modulaciones del sobreentendido afectuoso:

Rozas, que daba escalofríos a los hombres que le veían por primera vez, no intimidaba a los niños que se le acercaban espontáneamente; él los acariciaba [...] Los sábados como regla, eran innumerables los sobrinos de Rosas que iban a jugar a su casa con esta consigna paterna o materna: "Y pídele la bendición a tu tío"./ Los chiquillos iban y venían, entraban y salían, gritaban y si se encontraban en alguna de las piezas con su tío, este les decía: "Jueguen, diviértanse; pero no me toque los papeles, ni se vayan sin verme”./Así se hacía./Al ponerse el sol una sarta de sobrinos iba a buscar al tío; aunque estuviera ocupado escribiendo o con gente, los acogía risueñamente./ Todos por turno pedían la bendición, y todos por turno recibían un regalo idéntico que consistía en tres cosas: un peso fuerte (plata blanca), una docena de divisas coloradas y una litografía con el retrato de Quiroga, cuyas proporciones se contenían en una hoja como un pliego de papel de oficio abierto./Al dar esto último, Rozas decía (se lo decía a cada uno): "Tome ese retrato, sobrino; es de un amigo que los salvajes unitarios dicen que yo he mandado matar" (34). 
Si bien es cierto que el Rozas de Mansilla es ese tío a quién se le pide la bendición mientras se reciben de él tres clases de regalos donde el afecto se ve modulado por lo político (no olvidemos que se tratan de divisas coloradas y una litografía de Quiroga), es también un Rozas evocado para entender el presente (1898) inquiriendo el pasado desde una mirada que pretende adentrarse en el porvenir ("Entender el presente es inquirir el pasado: y, bien conocido lo actual, la mirada reflexiva penetra en lo porvenir, a la manera que el lente maravilloso nos ayuda, revelándonos que lo invisible para el ojo desnudo es un mundo fecundo, en cuya atmósfera hay seres, formas, ideas para el sabio” 23). Un Rozas que podría haber sido escrito -en parte, al menos- treinta y cinco años antes de esa fecha, pero entonces el tío hubiese sido una presencia histórico-política lo suficientemente potente como para contaminar aun más al sobrino. Un sobrino que adscribe al postulado de que

no se puede escribir, ni ensayando, la historia de una época representada por un hombre en el que se concentran todos los poderes, los más formidables, como disponer de la vida, del honor, de la fortuna de sus semejantes, sin buscar en sus antepasados, sino todo el misterio de su alma, algo así como la clave de algunos de sus rasgos prominentes, geniales; rasgos que llegan a ser, en ciertos momentos, como un contagio, bajo la influencia de su extraña, complicada y poderosa ecuación personal. (21)

Por otra parte, el “Rosas de treinta y cinco años antes” era el material político-literario de una generación de escritores (también políticos) donde lo familiar como intimidad no tenía cabida. El espacio que se jugaba en esa escritura era el público, es decir, aquel que ponía en funcionamiento las tramas genéricas de la diatriba, la polémica, el grito encendido. En ese espacio no había lugar para tíos ni sobrinos, sino para “un monstruo que [...] propone el enigma de la organización política de la República; [una] Esfinge Argentina, mitad mujer por lo cobarde, mitad tigre por lo sanguinario" (Facundo 241), por un lado, y para aquel o aquellos que finalmente descifraría(n) el enigma matando a la Esfinge con el objeto de dar "a la Tebas del Plata el rango elevado que le toca entre las naciones del Nuevo Mundo”.

En este marco no resulta difícil evaluar el silencio de ese sobrino quien por esos tiempos no debe haber tenido (o no puede haber tenido) mucho más que decir. Recordemos que Mansilla nace en el preciso momento en que Juan Manuel de Rosas asciende a la Suma del Poder, lo que quiere decir que vivió esa etapa fuerte de la historia argentina desde el lado de los "amigos" -más que eso, del de los "parientes", es decir, desde el costado familiar-del régimen. Adolfo Prieto plantea que el derrumbe de Rosas se produce cuando los hijos de estos amigos / parientes / familia son demasiado jóvenes como para haber sido llamados a ocupar un cargo en el gobierno (Popolizio). En el caso específico de Mansilla, casi diríamos que es ejemplar como rasgo de su vida el que continúe siendo para la mirada del otro, un hijo de, si no ya demasiado joven, sí demasiado contaminado como para ser llamado a ocupar algún lugar de privilegio en el espacio político, después de Caseros. Mansilla vive una larga historia que coincide cronológicamente con la historia de la constitución de la nación argentina moderna, sus hombres (Sarmiento, Mitre, Avellaneda, Roca, entre otros), proyectos, programas, éxitos y fracasos. Esta coincidencia cronológica 
le señala constantemente la filiación histórico-política de la cual proviene; señalamiento patético cuando no feroz que tiene en la biblioteca facciosa de una generación político / literaria su garantía de sobrevivencia. Generación que imprimiera cuanto comprimiera las fronteras de un paradigma semántico que figuró el corpus imaginario de Juan Manuel de Rosas y lo destinó (¿y condenó?) a permanecer y sostener varios de los “anaqueles” de la biblioteca facciosa del siglo xix; una biblioteca que, desde los "lomos” de sus textos, dibujara una enciclopedia tanto de prescripciones cuanto de proscripciones destinadas a normativizar un territorio de narraciones políticas para la nación argentina.

No podemos dejar de conectar una anécdota que consideramos emblemática en la historia de Mansilla y en Mansilla como historia. Lucio es sorprendido por el general Mansilla, su padre, leyendo en su estancia de Ramallo, El contrato social de Rousseau al mismo tiempo que es enfrentado por este con las siguientes palabras: "Mi amigo, cuando uno es sobrino de don Juan Manuel de Rosas, no lee El contrato social si se ha de quedar en este país, o se va de él si quiere leerlo con provecho”.

El peso de esta anécdota-que maliciosamente nos conecta con aquel otro "peso fuerte de plata blanca”, primer término de la trilogía de regalos infantiles emblemáticos- es uno de los pocos -si no el único- rasgo de centralidad visualizable en Mansilla; un peso que hace impacto y estalla en una multiplicidad de fragmentos -también emblemáticoscuando Rosas se ve expulsado del poder, evacuado del espacio público, mientras se convierte lentamente-una lentitud que recorre más de tres décadas-en un tío narrativizado a través del cual se inquiere casi con desesperación: "POR QUÉ esas cosas pasaron como se sabe [para poner] en la balanza a los unos y a los otros [mientras se les asigna] caritativamente la parte de responsabilidad que les corresponde” (55).

Sin embargo, es un "por qué” que recién podrá ser articulado veinte años después de la muerte de ese tío (1877), en las postrimerías de un siglo que permitirá resignificar (y, por ende, ayudar a evaluar) proyectos y programas; sobre todo cuando ese sobrino ha alcanzado una edad que le permite sentirse tanto un abuelo cuanto un hijo y siente que puede darse un plan para responder al interrogante (“[e]l plan será genético o cronológico en su conjunto, sin precisar fechas; no nos proponemos tampoco autorizar nuestra palabra con citaciones de documentos oficiales ni recortes de gacetas, teniendo una gran documentación en la cabeza, imágenes de impresiones pasadas, aunque no hayamos sido precisamente contemporáneos, y cuyas imágenes mnemónicas sentimos que podemos evocar con alguna vivacidad, como si los hechos remotos fueran incidentes de ayer" (15). Entonces, con menos desenfado que melancolía, se permite anunciar que, a pesar de todo ese peso de la historia es preferible hablar, lo que, en el caso de Mansilla, significa escribir, dado que tiene "a veces el silencio un no sé qué de deletéreo cuando se hace alrededor de los que necesitan que sus actos sean notados; callarlos es como un de profundis. Los derrotados no hablan, caminan mustios, con más o menos precipitación, meditando sobre los reveses de la fortuna” (41).

Tal vez también como un emblema -aunque resulte curioso categorizarla así en un siglo en el cual dicha figura siempre estuvo marcada por los tonos de la posesión, y en el caso de Mansilla estos adoptan los del despojo- podríamos evocar la ocasión en que Mansilla confirma que en el gobierno del presidente Sarmiento -y a pesar de todas las señales brindadas con respecto a su relación con Dominguito-su destino político sería tan 
solo el de ser un comandante de fronteras, en Río Cuarto, a las órdenes del general Arredondo. Pobre recompensa para quien se atribuía una parte principal en la elevación de Sarmiento al poder. Pero Lucio no era sensiblero. Sin embargo, el golpe había sido duro. Escribió con melancolía: "En este momento de mi vida represento el papel de un concurrente que no halla lugar ni de pie en la gran representación política, que él mismo ha organizado" (Popilizio 138).

Evidentemente el tema y el problema de Mansilla había sido siempre el de "hallar un lugar”, el que le fuera sucesivamente desplazado (en lo real y en lo imaginario) a una instancia de indeterminación crónica. Lo que Mansilla no estuvo nunca demasiado dispuesto a aceptar fue el hecho de que ese lugar había tenido su hora: era el lugar que le otorgaba el pertenecer a la familia de Rosas. Si bien la contaminación política que había generado la unión de sus padres le había garantizado un cierto grado de feroz benevolencia (valga el oxímoron) por parte de los opositores del "tirano", la biblioteca facciosa enunciada más arriba operaba como la paradoja garante de la memoria. Biblioteca facciosa y verborragia mansilleana son los términos de una memoria rencorosa que encuentra en el excéntrico Lucio su blanco privilegiado.

El general Roca le habría dicho: "Enciérrese en su casa por un año, no hable, no escriba y vendrán a buscarlo para hacerlo ministro”. Sin embargo... Lucio habla y escribe en razón de que sabe que el silencio es la verdadera garantía de su desaparición. En sus memorias acuña casi una aporía que podría funcionar en este trabajo como su carta de presentación: "Si pido no me dan y si no pido tampoco me dan” (Popolizio 20).

Soportando el peso de esta negatividad, Lucio escribe su Rozas, en tonos menores, a través de digresiones, de exabruptos, de miniaturas. Conversa -se ve impelido a conversar-acerca de todo aquello que para la centralidad del siglo xIx hubiera tenido que quedar al margen de la novela; un margen que leído desde la actualidad se vuelve una lúcida evaluación social de todos los proyectos que no hicieron de Mansilla un protagonista. Fin de esta escena de familia aunque inicio de uno de los más interesantes capítulos de la literatura autobiográfica ${ }^{5}$ que siempre oscilaría entre una curiosa actitud de condena al pasado rosista y de condena a la situación que le siguió y elaborada con un sistema de omisiones, de voluntarios silencios y de inexplicables reiteraciones que parecen depender menos de la fidelidad de la memoria que del canon faccioso impuesto por la biblioteca de la nación.

\section{BiBLIOGRAFÍA}

Alberdi, Juan B. Proceso a Sarmiento. [1852]. Buenos Aires: Caldén, 1967.

Area, Lelia y Cristina Parodi. "Escritura y silencio: el otro (?) Facundo de Sarmiento?” La imaginación histórica en el siglo XIX. Lelia Area y Mabel Moraña, comps. Rosario: UNR, 1994. 243-63.

Borges, Jorge Luis. “La biblioteca de Babel”. Obras Completas. [1944]. Buenos Aires: Emecé, 1975. 465-71.

${ }^{5}$ Capítulo que incluiría nombres tales como los de Guido, Calzadilla y Vicente Quesada. 
Jitrik, Noé. Muerte y resurrección de Facundo. Buenos Aires: CEDAL, 1968.

Matamoro, Blas. “La (Re)Generación del 37”. Punto de Vista 28 (1988): 27-39.

Mansilla, Lucio V. Rozas. Ensayo histórico-psicológico. [1898]. Buenos Aires: Bragado, 1967.

Palcos, Alberto. Sarmiento. Buenos Aires: Ateneo, 1938.

Prieto, Adolfo. La literatura autobiográfica argentina. Buenos Aires: Jorge Alvarez, 1966.

Popolizio, Enrique. Vida de Lucio V. Mansilla. Buenos Aires: Pomaire, 1985.

Ravignani, Emilio. Inferencias sobre Juan Manuel de Rosas y otros ensayos. Buenos Aires: Huarpes, 1937.

Said, Edward. Culture and Imperialism. New York: Alfred A. Knopf, 1993.

Sarmiento, Domingo F. Facundo o civilización y barbarie. [1845]. Buenos Aires: Sopena, 1958.

Recuerdos de provincia. [1850]. Caracas: Ayacucho, 1991.

Viñas, David. Literatura argentina y realidad política. Buenos Aires: Jorge Alvarez Ediciones, 1964.

Literatura argentina y realidad política. Apogeo de la oligarquía. Buenos Aires: Siglo Veinte, 1975.

White, Hayden. “La cuestión de la teoría historiográfica actual”. El contenido de la forma. Narrativa, discurso y representación histórica. [1987]. Barcelona: Paidós, 1992. 4174. 